\title{
Subarachnoid hemorrhage The long and short of it
}

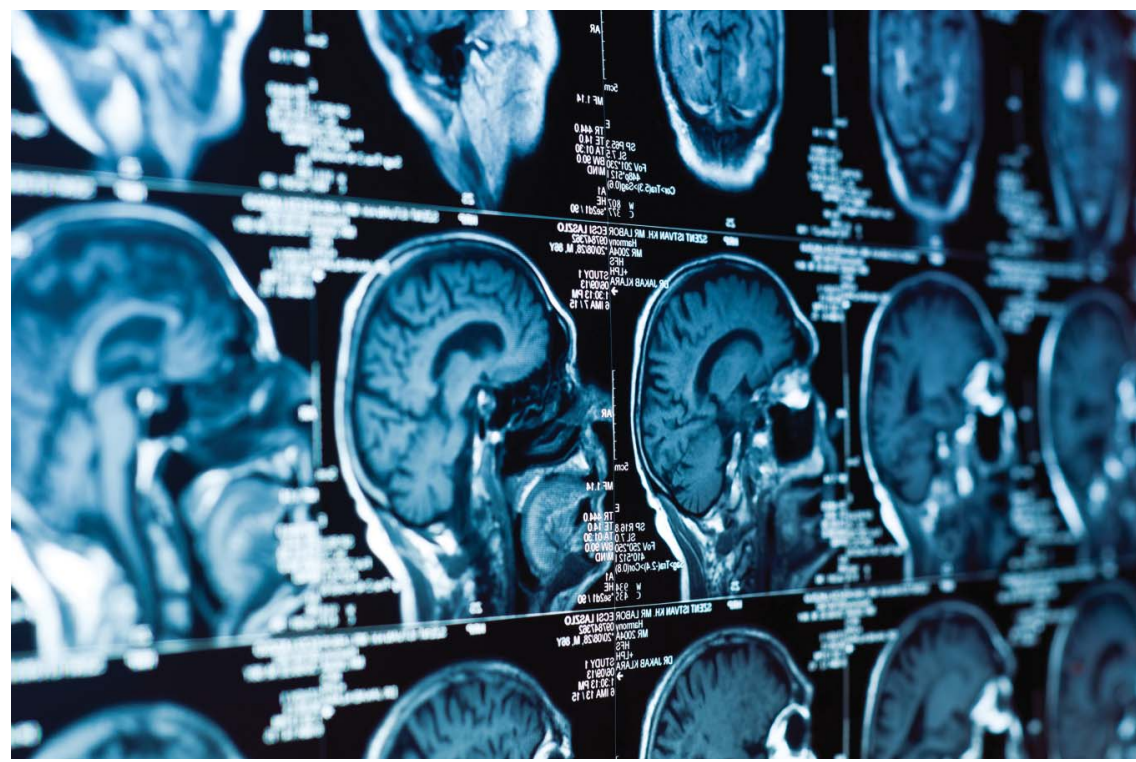

In their article "Short- and long-term outcomes of patients with aneurysmal subarachnoid hemorrhage," Dr. Roquer et al. ${ }^{1}$ set out to answer some important questions about a serious neurologic problem. Their questions were simple: If a person has a subarachnoid hemorrhage (SAH), what happens? What are the problems that occur right away? What are the long-term concerns? The authors looked to prior publications for these answers. However, many of the studies were old. How accurate was this information? Since these studies were done, there have been many advances in surgical techniques. There also have been many developments in technology. The ability to approach problems from within the blood vessel itself, known as endovascular surgery, has changed considerably. Perhaps these advances have led to improved outcomes for people who have had an $\mathrm{SAH}$.

\section{How was the study done?}

Dr. Roquer and the other authors work in Barcelona at the Hospital del Mar. The Hospital del Mar is a specialized stroke referral center in Catalonia, Spain, where there are 7.4 million people. At this medical center, there is a team of doctors and nurses, highly trained in the diagnosis and treatment of SAH. The authors carefully evaluated 476 people who were admitted to the hospital for SAH between January 2007 and December 2018. They looked at the type, location, and severity of each patient's SAH. They evaluated the group of patients for risk factors for SAH, and carefully followed them to watch for any later complications of the SAH. Mortality after SAH was recorded at 1 week, 3 months, 1 year, and 5 years. Neurologic impairment was measured using a standard scale called the modified Rankin Scale at 3 months, 1 year, and 5 years.

\section{What were the results?}

As noted, the authors identified 476 total patients who had had SAH during the mentioned timeframe. Because the authors were interested in studying SAH that occurred due to aneurysms, they excluded patients whose SAH was due to other causes or for whom the cause
Related Article

Short- and longterm outcome of patients with aneurysmal subarachnoid hemorrhage

http://dx.doi.org/10.1212/ WNL.0000000000010618 
was unknown. This narrowed the group to 347. Of these, 311 had been treated with either surgical clipping (69 patients, or $22.2 \%$ of the 311 patients) or an endovascular procedure (242 patients, or $77.8 \%$ of the group of 311 ). Thirty-six people from the group of 347 were not treated because they were so sick when they arrived that treatment would have been ineffective, or because it was determined that the aneurysm could not be treated with either procedure.

The authors followed the patients for an average of 43.4 months. Mortality was $8.7 \%$ at 1 week, $18.4 \%$ at 3 months, $22.9 \%$ at 1 year, and $29 \%$ at 5 years. This was similar to the rates seen in other studies. Poor neurologic outcome, as defined by the modified Rankin Scale, was $43.3 \%$ at 1 month and $36 \%$ at both 1 and 5 years. Because the information was gathered over 10 years, the authors further broke down the patient group based on the years of the study. They looked at the patients from the first half (2007-2012, 155 patients) and the second half (2013-2018, 156 patients) of the study. There was no difference in mortality or in neurologic outcome between these 2 groups.

Next, they compared the neurosurgery group (patients who were treated with aneurysm clipping) to the endovascular group (patients who were treated with coils and stents). There was no difference in the complications that each group experienced. In the neurosurgical group, people more often needed the temporary use of a ventilator. In addition, people who had brain surgery stayed in the hospital longer, by about 2 days. As anticipated, people who had larger brain bleeds and those who had more complications had a higher risk of dying or having more severe, longer-lasting neurologic problems after SAH.

\section{Why is this important?}

There are many important differences between the study by Dr. Roquer et al. and past studies. First, Dr. Roquer et al. looked at all people admitted with SAH. In some past studies, only patients in the intensive care unit (ICU) were evaluated. The fact that all were in the ICU might suggest that they were sicker, and therefore that information from those studies may pertain only to people with more severe $\mathrm{SAH}$. Also, many of the older studies followed patients for a shorter time frame than 5 years. They lacked the long-term data that this study presented. Next, many of the other studies were limited because of patient dropout. Many of the people who were initially part of the study did not return for further evaluation. This might mean that the results of the older studies were inaccurate. In this study, there was no difference in the outcomes of the people who had neurosurgery (aneurysm clipping) vs those who had an endovascular procedure (coils or stents). Notably, given the seriousness of $\mathrm{SAH}$, at 5 years, $2 / 3$ of the patients in this study had survived without neurologic complications. 


\section{About subarachnoid hemorrhage}

\section{What is a subarachnoid hemorrhage?}

The brain is surrounded by fluid. This fluid is called CSF. In a sense, the brain floats within this fluid. But the brain is not floating like a cork in water. Instead, the brain is supported and held in place by a very strong web-like structure called the arachnoid mater, which is one of the coverings of the brain. The arachnoid acts like a scaffold: CSF can flow between the support columns, moving around the brain, washing away waste products that the brain cells produce. If bleeding occurs in this fluid-filled space, it is called SAH.

SAH can be caused by many things. By far, the most common cause is head trauma. Second to trauma is bleeding due to a ruptured aneurysm. Aneurysms are bulging of a weakened part of the wall of an artery. The person's blood pressure causes the weak part of the wall to balloon outward. Because this part of the artery is weak, it is prone to bursting or rupturing. When this occurs, the blood goes into the arachnoid space around the brain. In other words, SAH occurs.

\section{What are the signs of SAH?}

One of the most common signs of SAH is a sudden, severe headache. Many people who have had this describe the headache as "the worst of my life." The sudden nature this headache is often described as "thunderclap." When bleeding occurs around the brain, it is very irritating to the brain. A person may experience nausea, vomiting, neck pain, and back pain. They may have dizziness, and in some cases, seizures.

\section{How is SAH diagnosed?}

There are many tests that can identify an SAH. One of the most common is a CT scan. MRI may also identify SAH. In some people, if bleeding is suspected but not apparent on either CT or MRI, a lumbar puncture (also commonly called a spinal tap) may be performed. During a lumbar puncture, a needle is used to take a sample of the CSF. If bleeding has occurred, it is easily seen in the sample of CSF.

\section{What is the treatment of SAH?}

When an SAH occurs, the cause of the SAH must be identified. The reason is simple: one of the treatments of $\mathrm{SAH}$ is to eliminate the cause. If the cause is a ruptured aneurysm, the treatment would be to treat the aneurysm, in order to prevent possible future rebleeding. Nowadays, aneurysms are most often treated using endovascular procedures. A thin catheter is placed in the affected artery and threaded to the location of the aneurysm. Tiny platinum coils are placed in the aneurysm itself, causing the aneurysm to clot, and reducing the risk of rebleeding. Stents are also used. These are placed inside the blood vessel, excluding the aneurysm from the artery to which it is connected. This isolates the aneurysm from the person's circulation so it can no longer bleed. Often, the endovascular procedure may use a combination of both coils and stents. In some people, an endovascular procedure may not be possible. For these people, neurosurgery is needed. The surgeon opens the skull and places a clip over the aneurysm, preventing it from causing problems.

The second part of the treatment of SAH is to prevent complications that might occur due to the subarachnoid bleeding. For instance, SAH can sometimes cause vasospasm, or a constriction of blood vessels. This most often happens 7-10 days after an SAH occurs. In the hospital, ultrasound testing (called Doppler) is used to look for this complication. If suspected, medications may be needed. In other people, seizures may occur, necessitating treatment.

The modern treatment of SAH requires a team of experts. These experts are highly trained, and work in specialized medical centers that have access to and experience in advanced endovascular and neurosurgical procedures. The team of experts often includes a neurologist (usually a stroke specialist), a neurosurgeon, and a neurointerventionalist. The neurointerventionalist is a person who has been specially trained to perform the delicate endovascular coiling and stenting procedures. The person who had the SAH will likely be in the ICU-they would need the expertise of a neurointensivist, a doctor who has been specially trained in neurologic intensive care. When SAH occurs, many people develop neurologic problems such as weakness. Because of this, the team of experts also includes doctors and nurses who are trained in rehabilitation medicine, physical therapy, and occupational therapy. By working closely together, the team quickly diagnoses and treats the problem and addresses any complications and neurologic problems that occur.

\section{For more information}

\section{Brain \& Life}

brainandlife.org

\section{Brain Aneurysm Foundation \\ bafound.org/}

The Bee Foundation

thebeefoundation.org/

\section{References}

1. Roquer J, Cuadrado-Godia E, Guimaraens L, et al. Shortand long-term outcome of patients with aneurysmal subarachnoid hemorrhage. Neurology 2020;95:e1819-e1829.

2. Cleveland Clinic. Available at: my.clevelandclinic.org. Accessed July 24, 2020. 


\title{
Neurology
}

\author{
Subarachnoid hemorrhage: The long and short of it \\ Steven Karceski \\ Neurology 2020;95;e1915-e1917 \\ DOI 10.1212/WNL.0000000000010642
}

This information is current as of September 28, 2020

\section{Updated Information \&} Services

References

Permissions \& Licensing

Reprints including high resolution figures, can be found at: http://n.neurology.org/content/95/13/e1915.full

This article cites 1 articles, 1 of which you can access for free at: http://n.neurology.org/content/95/13/e1915.full\#ref-list-1

Information about reproducing this article in parts (figures,tables) or in its entirety can be found online at:

http://www.neurology.org/about/about_the_journal\#permissions

Information about ordering reprints can be found online:

http://n.neurology.org/subscribers/advertise

Neurology ${ }^{\circledR}$ is the official journal of the American Academy of Neurology. Published continuously since 1951, it is now a weekly with 48 issues per year. Copyright (C 2020 American Academy of Neurology. All rights reserved. Print ISSN: 0028-3878. Online ISSN: 1526-632X.

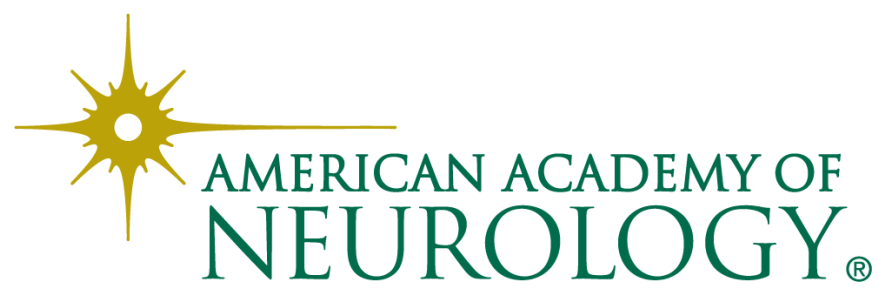

